\title{
The effect of storage on spermatozoa in vitro and the composition of the extender on the proportion of offspring from heterospermic insemination in the chicken
}

\author{
P. A. Martin* and P. J. Dziuk \\ Department of Animal Science, University of Illinois, Urbana, Illinois 61801, U.S.A.
}

\begin{abstract}
Summary. Spermatozoa from a Columbian (C) and a Leghorn (L) cock were stored at $4^{\circ} \mathrm{C}$ for $4 \mathrm{~h}$ before mixing in equal numbers for insemination. When hens were inseminated with either $100 \times 10^{6}, 200 \times 10^{6}$ or $300 \times 10^{6}$ spermatozoa, the proportion of chicks sired by Cocks $C$ and $L$ was not affected $(P>0.05)$ by the total number of spermatozoa inseminated or the interval from insemination to oviposition (2-16 days). Cock $\mathrm{C}$ sired $61 \%$ of the chicks after the 4 -h storage period. In a concurrent study Cock $\mathrm{C}$ was found to sire $34 \%$ of the offspring when fresh semen was used, indicating that the relative fertilizing ability of spermatozoa from different males does not change during storage in vivo, but may do so during storage in vitro.

Ringer's solution $(R)$ was compared to Locke's solution $(O)$ in its ability to maintain the fertilizing ability of spermatozoa. Spermatozoa from Cocks $C$ and $L$ were stored in either $\mathbf{R}$ or $\mathbf{O}$ and then mixed in $\mathbf{a} 1: 1$ ratio in the four combinations: $C R+L R$, $\mathrm{CO}+\mathrm{LO}, \mathrm{CR}+\mathrm{LO}$, and CO + LR. When the same extenders were used for both cocks, i.e. $\mathrm{CR}+\mathrm{LR}$ and $\mathrm{CO}+\mathrm{LO}$, differences between groups were not significant $(P>0.05)$ for the number of eggs collected, the $\%$ of eggs fertilized and the proportion of chicks sired by each cock. With the combinations CR + LO and CO + LR, the number of eggs collected, the \% of eggs fertilized, and the number of chicks in the two groups were similar. The CR + LO combination resulted in $57 \%$ of the chicks being sired by Cock $\mathrm{C}$, but the proportion of chicks sired by this cock rose significantly $(P<0.005)$ to $77 \%$ when the CO + LR combination was used. This $20 \%$ increase was presumably due to the advantage of storage in the $\mathbf{O}$ extender and indicates that appropriate heterospermic inseminations are more sensitive than homospermic insemination for evaluating treatments applied to semen.
\end{abstract}

\section{Introduction}

The artificial insemination of an equal number of spermatozoa from two males usually results in one male siring most of the offspring (Beatty, 1960; Roche, Dziuk \& Lodge, 1968; Beatty, Bennett, Hall, Hancock \& Stewart, 1969; O'Reilly, Graves \& Dziuk, 1972). The proportion of offspring sired by competing males is not influenced by the total number of spermatozoa inseminated, breed of female, or the period of storage in the female (Allen \& Champion, 1955; Stewart, Spooner, Bennett, Beatty \& Hancock, 1974), but is influenced by the ratio of spermatozoa from each male (Martin, Reimers, Lodge \& Dziuk, 1974). Storage in vitro and the method of processing of semen is known to influence the proportion of offspring in rabbits (Roche et al., 1968; O'Reilly et al., 1972).

The following experiments were performed to determine the effect of storage in vitro and the difference between two extenders on the proportion of offspring from two cocks.

\section{Materials and Methods}

The management of the chickens and procedure for processing and handling the eggs and semen were as described previously (Martin et al., 1974). The two cocks used in this study were the Columbian

* Present address: Department of Animal Science, Macdonald Campus of McGill University, Ste. Anne de Bellevue, Quebec, Canada, HOA ICO. 
$\left(C_{1}\right)$ and Leghorn $\left(L_{1}\right)$ used in concurrent studies reported previously (Martin et al., 1974; Martin \& Dziuk, 1977). In Exp. I, the ejaculates were extended with an equal volume of modified Ringer's (R) solution (Table 1). Each sample was stored separately for $4 \mathrm{~h}$ at $4^{\circ} \mathrm{C}$ before preparing a single mixture with equal numbers of spermatozoa from each cock. Three groups of $11 \mathrm{~L}$ hens each were inseminated with a total of $100 \times 10^{6}, 200 \times 10^{6}$ or $300 \times 10^{6}$ spermatozoa from each mixture. The volume of each inseminate was directly proportional to the total number of spermatozoa inseminated.

Table 1. Composition of semen extenders ( $g /$ litre)

\begin{tabular}{lcllllc}
\hline Extender & $\mathrm{NaCl}$ & $\mathrm{KCl}$ & $\mathrm{CaCl}_{2}$ & $\mathrm{NaHCO}_{3}$ & Glucose & $\mathrm{MgSO}_{4}$ \\
\hline Ringer (R) & 6.8 & 1.733 & 0.642 & 2.45 & - & 0.25 \\
Locke (O) & 9.2 & 0.42 & 0.12 & 0.15 & 1.0 & - \\
\hline
\end{tabular}

In Exp. II, half of each $C_{1}$ and $L_{1}$ ejaculate was adjusted to contain $100 \times 10^{6}$ spermatozoa in $0.1 \mathrm{ml}$ of either $\mathrm{R}$ or Locke's (O) solution (Table 1) and stored for $4 \mathrm{~h}$. Just before insemination, the samples were mixed in equal volumes to produce the 4 possible male-extender combinations, $\mathrm{CR}+\mathrm{LR}, \mathrm{CO}+\mathrm{LO}, \mathrm{CR}+\mathrm{LO}$ and $\mathrm{CO}+\mathrm{LR}$, each containing an equal number of $\mathrm{C}$ and $\mathrm{L}$ spermatozoa. Four groups of $42 \mathrm{~L}$ hens each were inseminated. Each hen received $100 \times 10^{6}$ spermatozoa.

Eggs from inseminated hens were collected daily beginning 2 days after insemination for a period of 15 days for Exp. I and 10 days for Exp. II. The data were analysed by $\chi^{2}$ tests.

\section{Results}

The results of Exp. I are shown in Table 2. Of the 397 eggs gathered, 191 were fertile and 10 had dead embryos. A test of homogeneity revealed that the proportion of offspring did not differ significantly $(P>0.05)$ with the total number of spermatozoa inseminated. The proportion of offspring from the $\mathrm{C}$ cock for Exp. I differed significantly $(P<0.005)$ from the $50 \%$ that would be expected if each spermatozoon in the mixture was equally capable of fertilizing an egg. The interval from insemination to oviposition did not affect the proportion of offspring from each male.

Table 2. Effect of total number of spermatozoa and the period of storage in vivo on the proportion of offspring in the chicken after heterospermic insemination

\begin{tabular}{|c|c|c|c|c|c|c|c|c|}
\hline \multirow[b]{3}{*}{$\begin{array}{l}\text { No. of sperm. } \\
\qquad\left(\times 10^{6}\right)\end{array}$} & \multicolumn{8}{|c|}{ Days from insemination to oviposition } \\
\hline & \multicolumn{2}{|r|}{$2-16$} & \multicolumn{2}{|r|}{$2-6$} & \multicolumn{2}{|r|}{$7-11$} & \multicolumn{2}{|c|}{$12-16$} \\
\hline & $\begin{array}{l}\text { No. of } \\
\text { chicks } \\
\text { hatched }\end{array}$ & $\begin{array}{c}\text { Chicks } \\
\text { sired by } \\
\text { Cock C }(\%)\end{array}$ & $\begin{array}{l}\text { No. of } \\
\text { chicks } \\
\text { hatched }\end{array}$ & $\begin{array}{c}\text { Chicks } \\
\text { sired by } \\
\text { Cock C }(\%)\end{array}$ & $\begin{array}{l}\text { No. of } \\
\text { chicks } \\
\text { hatched }\end{array}$ & $\begin{array}{c}\text { Chicks } \\
\text { sired by } \\
\text { Cock C }(\%)\end{array}$ & $\begin{array}{l}\text { No. of } \\
\text { chicks } \\
\text { hatched }\end{array}$ & $\begin{array}{c}\text { Chicks } \\
\text { sired by } \\
\text { Cock C }(\%)\end{array}$ \\
\hline 100 & 43 & 53 & 26 & 50 & 12 & 67 & 5 & 40 \\
\hline 200 & 61 & 61 & 35 & 60 & 21 & 62 & 5 & 60 \\
\hline 300 & 77 & 65 & 42 & 71 & 31 & 58 & 4 & 50 \\
\hline Total & 181 & $61^{*}$ & 103 & $62 \dagger$ & 64 & $61 \dagger$ & 14 & $50+$ \\
\hline
\end{tabular}

* Significantly different from $50 \%(P<0.005)$.

$\uparrow$ Proportions do not differ from each other $(P>0.05)$.

The results of Exp. II are shown in Table 3. When the results of the four cock-extender combinations were combined, the $\mathrm{C}$ cock sired $67.5 \%$ of 502 chicks. Except for mixture $\mathrm{CR}+\mathrm{LO}$, the percentage of chicks sired by the $\mathrm{C}$ male was greater $(P<0.005)$ than the $50 \%$ that would be expected if each spermatozoon in the mixture was equally capable of fertilizing an egg. When spermatozoa from both cocks were stored and inseminated in the same extender in combinations $\mathrm{CR}+\mathrm{LR}$ and $\mathrm{CO}+\mathrm{LO}$, the percentage of chicks sired by Cock $\mathrm{C}$ were nearly identical for the two extenders. The weighted mean 
Table 3. Fertility and percentage of chicks sired by Cocks $C$ and $L$ after storage of semen in vitro in 2 extenders, Ringer (R) or Locke (O), for $4 \mathrm{~h}$ at $4^{\circ} \mathrm{C}$

\begin{tabular}{lcccc}
\hline & \multicolumn{4}{c}{ Male-extender combinations } \\
\cline { 2 - 5 } & CR + LR & CO + CO & CR + LO & CO + LR \\
\hline Total no. of eggs & 295 & 304 & 288 & 290 \\
$\%$ of eggs fertilized & $37 \dagger$ & $42 \dagger$ & $45^{*}$ & $55^{*}$ \\
No. of dead embryos & 3 & 3 & 7 & 14 \\
Total no. of chicks & 107 & 125 & 124 & 146 \\
$\%$ of chicks sired by Cock C & $67.3 \ddagger$ & $67.2 \ddagger$ & $57.3 \S$ & $76.7 \S$ \\
\hline
\end{tabular}

$* \ddagger$ Values not significantly different from each other $(P>0.05)$. $\S$ Values significantly different from each other $(P<0.005)$.

of the percentage of chicks sired by Cock $\mathrm{C}$ was $67 \cdot 2 \%$. The number of eggs collected, the percentage of eggs fertilized, and the number of chicks resulting from these 2 mixtures were not different $(P>0.05)$.

There was no difference $(P>0.05)$ in the number of eggs collected, the percentage of eggs fertilized and the number of chicks for the insemination combinations of CR + LO and CO + LR. Spermatozoa stored in the $O$ extender gave rise to 165 of the 270 chicks whereas spermatozoa stored in $\mathrm{R}$ produced the other 105 chicks. The difference between combinations in the proportion of offspring sired by Cock $C$ was highly significant $(P<0.005)$. Paternity was not established for 27 embryos in Exp. II, and of the 1177 eggs gathered $45 \%$ were fertile.

\section{Discussion}

When spermatozoa from a cock were stored before mixing with equal numbers of stored spermatozoa from another cock, the proportion of offspring from each cock after insemination of this mixture was not equal. The number of days the spermatozoa spent in the hen's oviduct before fertilization did not influence the proportion of chicks sired by each cock (Table 2). Whatever advantage spermatozoa from one male have over those from another does not change with ageing or storage in vivo. This is in agreement with the report of Martin et al. (1974). This would indicate that the differences are innate in the spermatozoa and are not imparted by the hen.

Quite the opposite seems to be true after storage in vitro. Cock $C_{1}$ was used in competition with $L_{1}$ in many experiments conducted concurrently with the present study (Martin et al., 1974; Martin \& Dziuk, 1977) in which the spermatozoa were mixed in equal numbers within a few minutes after collection and inseminated immediately. Cock $\mathrm{C}_{1}$ sired $34 \%$ of chicks under those conditions whereas in the present study after $4 \mathrm{~h}$ of storage at $4^{\circ} \mathrm{C}$ he sired $61 \%$ of the chicks in Exp. I and $67 \%$ of the chicks in Exp. II. This shift in the heterospermic dominance of males after storage of spermatozoa in vitro was noted previously in the rabbit (Roche et al., 1968; O'Reilly et al., 1972). A possible explanation based on differential maturity rates of spermatozoa was proposed by $O$ 'Reilly et al. (1972). The observations in the present work with the chicken corroborate the previous observations in the rabbit, indicating that the phenomenon may be a general one. If the phenomenon is applicable to other species and storage conditions, there is the possibility that many present evaluations based on homospermic inseminations may be misleading. A male with higher fertility than another male when fresh semen is used, may have lower fertility with stored semen. Tests for fertility of a male should be made using only the storage period of semen that will be used in practice. Assuming that fertility of males is to any extent heritable and selecting on the basis of only one storage period may lead to a reduced fertility of the offspring when spermatozoa are used under other conditions. The lack of relationship between fertility of unfrozen semen and deep frozen semen in cattle may be an example of this (Stewart et al., 1974). 
In Exp. II, semen was stored for a relatively short time in two extenders that differed mainly by the presence of glucose in the Locke's $(O)$ extender. The level of fertility after insemination of semen stored in either extender did not differ significantly even though 599 eggs were examined. When competitive fertilization between spermatozoa stored in the two extenders was used as the method for distinction, the differences were highly significant and apparent. This observation reaffirms previous findings that the application of the competitive fertilization technique enables one to distinguish clearly between subtle differences in extenders and methods of handling semen that escape detection by usual homospermic methods. With the advent of other means of identifying which spermatozoon fertilizes which egg, the heterospermic method should be even more useful (Bedford \& Overstreet, 1972; Pursel, Johnson \& Borkovec, 1975).

\section{References}

Allen, C.J. \& Champion, L.R. (1955) Competitive fertilization in the fowl. Poult. Sci. 34, 1332-1342.

BeATTY, R.A. (1960) Fertility of mixed semen from different rabbits. J. Reprod. Fert. 1, 52-60.

Beatty, R.A. Bennett, G.H., Hall, J.G., Hancock, J.L. \& StewaRT, D.L. (1969) An experiment with heterospermic insemination in cattle. J. Reprod. Fert. 19, 491-502.

BedFord, J.M. \& OVerstreet, J.W. (1972) A method for objective evaluation of the fertilizing ability of spermatozoa irrespective of genetic character. $J$. Reprod. Fert. 31, 407-414.

MarTIN, P.A. \& DzIUK, P.J. (1977) Assessment of relative fertility of males (cockerels and boars) by competitive mating. $J$. Reprod. Fert. 49, 323-329.

Martin, P.A. Reimers, T.J., Lodge, J.R. \& DziUK, P.J. (1974) The effect of ratios and numbers of spermatozoa mixed from two males on proportions of offspring. $J$. Reprod. Fert. 39, 251-258.

O'Reilly, P.J., Graves, C.N. \& Dziuk, P.J. (1972) Heterospermic insemination as a means of evaluating techniques of semen handling. J. Reprod. Fert. 29, 49-56.

Pursel, V.G., Johnson, L.A. \& Borkovec, A.B. (1975) Effects of in-vitro treatment of boar spermatozoa with TEPA on the fertilization and development of pig eggs. J. Reprod. Fert. 45, 549-552.

Roche, J.F., DzIUK, P.J. \& LodGe, J.R. (1968) Competition between fresh and aged spermatozoa in fertilizing rabbit eggs. J. Reprod. Fert. 16, 155-159.

SteWART, D. L., SPOONER, R.L., BENNETT, G.H., BeATTY, R.A. \& HANCOCK, J.L. (1974) A second experiment with heterospermic insemination in cattle. J. Reprod. Fert. 36, 107-116.

Received 13 November 1976 